\title{
Papers
}

\section{Segmentation and satisfaction preferences of specific Looking Glass Cohorts profiles: A case study of the timeshare industry}

Received (in revised form): 28 November 2005

\section{Randall Upchurch}

is Professor of Timeshare Development in the Rosen College of Hospitality Management at the University of Central Florida located in Orlando, Florida. He has over 21 years of experience in the lodging industry, working 16 years for a variety of hotel companies, including Drury Inns, Hilton, Holiday Inns, Ramada Inn and Red Roof Inns. In his present position at the University of Central Florida, Dr Upchurch is actively working with the American Resort Development Association to deliver a minor in timeshare development. These courses include the (a) Principles of Resort Timesharing, (b) Development of Vacation Ownership Resorts, (c) Management of Vacation Ownership Resorts, (d) Timeshare Sales Tactics and Marketing Strategy Deployment and (e) Management of Marketing Intelligence Systems.

\section{Paul Rompf}

joined the faculty of the Rosen College of Hospitality Management in August of 2002. This followed more than four years of teaching and administrative responsibilities at the Australian International Hotel School in Canberra, Australia, where he held the positions of Assistant Dean - Research \& Development and Assistant Dean - Academic Affairs. Early in his academic career, he directed the development and progress of a then new baccalaureate program in Hotel \& Restaurant Administration at the University of Southern Mississippi. Beyond this, he has many years of experience in multiple facets of the hospitality industry.

\section{Denver Severt}

has been an associate professor at the Rosen College of Hospitality Management for three years. Prior to this, he had taught seven years at Eastern Michigan University. His research pivots around topics that relate to the customer's path to loyalty. Before joining academe, Denver worked in restaurant venues and country clubs for 25 years. He teaches graduate and undergraduate courses in accounting and guest service management for the Rosen College.

Randall Upchurch University of Central Florida Rosen College of Hospitality Management

Tel: +14079038048 Fax: +14079038105 E-mail: rupchurc@mail.ucf.edu

\begin{abstract}
The Looking Glass Cohort's segmentation scheme was used to classify members of a timeshare ownership vacation club. The Cohort segments were analysed for differences in measures of satisfaction among the timeshare owners. An analysis of variance showed that the satisfaction indices, in general, were favourable between groups. The results further suggested that this particular timeshare developer has targeted niche groupings of timeshare prospects signalling divergent leisure and recreational preferences in property offerings and, in doing so, has satisfied members across the niche. Some areas of improvement on a segment-by-segment basis were also found.
\end{abstract}




\section{Keywords:}

market segmentation, Looking Glass Cohorts, timeshare, lifestyle segmentation, vacation club

Journal of Retail and Leisure Property (2006) 5, 173-184.

doi:10.1057/palgrave.rlp.5100015

\section{INTRODUCTION}

The 1960s epoch is etched in US history as the dawn of rapid social change, but it also ushered in a dramatic change in how entrepreneurs and business enterprises began to view their customers. A default homogeneous customer perception began to evaporate into a heterogeneous population of consumers that could be segmented into homogeneous subsets. This also was the decade in which a European developer known as Superdevolvy began offering timeshare intervals at a ski resort in the French Alps for ski resort enthusiasts. ${ }^{1}$ The basic concept proffered by Superdevolvy is not largely different from how timeshare is sold in the 21st century in that Superdevolvy sold individual units to multiple owners for a specified period of time. In essence, a single leisure-related product was no longer viewed as 'right' for all customers because of unique needs associated with how the product was to be used, experienced or other important expectations and outcomes to the consumer.

\section{MARKET SEGMENTATION - A BRIEF REVIEW OF SEGMENTATION APPROACHES}

Segmenting consumer markets is a long-accepted practice in the hospitality and tourism industries that extends beyond the hotel companies noted below as well as in various tourist settings. ${ }^{2,3}$ For instance, traditional lodging properties providing overnight accommodations to the travelling public continue to evolve, with "new properties' increasingly targeting more highly defined niche segments of the population. Marriott exemplifies this trend, with some of its more recent additions being TownPlace Suites, SpringHill Suites, Marriott Vacation Club and Marriott Villa Vacations, with the latter two being timeshare properties. Marriott, however, is not the only lodging company that has found segmentation to be profitable within their timeshare divisions. Such practices are also evident in timeshare offerings by Four Seasons, Hilton, Hyatt, Starwood and Wyndham Resorts. ${ }^{4}$

In the period of the 21st century, it appears that the timeshare industry is more rigorously embracing the concept of demographic and lifestyle segmentation when targeting their existing and potential customers. This is a radical change from early practices that largely appeared to be a broad-based approach to attracting potential purchasers, thus potentially explaining why the timeshare industry has historically been labelled as being aggressive in their sales and marketing approaches. ${ }^{5}$

Initial efforts in distinguishing between different market segments utilized population demographics to divide a heterogeneous target population into more homogeneous subsets. Although a relatively easy segmentation scheme to implement, common demographic characteristics were soon recognized for inherent inadequacies in predicting consumer 
needs that ultimately translate into products and services being demanded. To counter the inadequacies associated with demographic segmentation, psychographic segmentation approaches, such as VALS and PRIZM, were designed to probe into the human psyche for information on individuals' activities, attitudes, interests and opinions. Psychographic segmentation also incorporates demographic and geographic attributes resulting in unique and detailed profiles that represent homogeneous subsets of consumers. The net result is a richer, more definitive snapshot of each subset that can be interpreted for application to consumer purchase motivations and that further translates into specific products or services to be demanded. ${ }^{6}$

Another segmentation tool known as the Looking Glass Cohorts (hereafter referred to as Cohorts) is a household-based segmentation tool that facilitates marketers understanding, targeting and communicating of potential customers. ${ }^{7}$ According to the Cohort typology, there are four broad consumer segments - Couples, Females, Males and Composite. The Couples category is further divided into 13 subsegment clusters, the Female classification is subdivided into nine types, and the Male classification is divided into eight types. The Composite classification functions as a 'miscellaneous, hard-to-classify segment.

\section{APPLICATIONS OF THE LOOKING GLASS COHORTS TO TIMESHARE PROPERTY OFFERINGS}

Successive application of The Looking Glass Cohorts is found in yearly reports by Ragatz Associates, with the most recent available being their 2003 resort timesharing report. These reports provide tangible evidence that different property consumption preferences exist among timeshare owners, and these lifestyle preferences assist developers in targeting future purchasers. One limitation to note is that the Ragatz and Associates studies include timeshare owners who use RCI's resort exchange services, and is therefore representative of differing quality levels, geographical locations and recreational preferences within RCI's directory of timeshare resorts. This, in essence, means that the Ragatz and Associate studies represent a broad base of market segments.

According to the 2003 Ragatz study, timeshare purchasers were predominantly characterized as (Looking Glass also assigned names to add a more 'human' touch) mature couples (Burt \& Marilyn), upscale middle-aged couples (Stan \& Carole), affluent professional couples (Barry \& Kathleen) and affluent empty nesters (Alex \& Judith). Overall, timeshare consumers fitting these profiles accounted for 48.4 per cent of RCI's timeshare resort owners. Couples with children were in another five groupings: affluent couples with kids (Jeffrey \& Ellen), teen-dominated families (Danny \& Vickie), young families (Chad \& Tammie) and back to school families (Todd \& Wendy). These accounted for another 30.8 per cent of the recent timeshare purchasers. From a macro-view, this means that approximately 79 per cent of the most recent timeshare purchasers were families with only 13 per cent being single households.

Demonstrating the diversity of lifestyles, Ragatz and Associates asserted that the mature couples' (Burt \& Marlyn) Cohort type placed a 
high level of importance on the timeshare company's credibility, were close to retirement with no children at home, were active investors and were active travellers. The Stan \& Carole Cohort type were upscale middle-aged couples (49 years of age) who maximized their value by purchasing single weeks, biennials or points, were drawn by the credibility of the timeshare developer, not financially hampered by children, were dual-income households (median income of \$73,500) and enjoyed outdoor activities. The Jeffrey \& Ellen type were middle-aged (42 years of age) affluent couples (median income of $\$ 144,800$ ) with children, purchased single to multiple week products in tourist destinations that favour snow skiing or tropical areas, lived in urban areas, were connoisseurs of culture and very active in recreational activities. Danny \& Vickie were described as teen-dominated families that were approximately 42 years of age and average household income of $\$ 56,200$. This Cohort type had a preference for three-bedroom villas, single weeks, and mountain and tropical locations. The Andrea Cohort type earns a median income of $\$ 48,900$, had a median age of 39 years, was a single career-focused mom, purchased two-bedroom villas, and had a preference for beach, attraction and entertainment locations. The upscale mature woman (Virginia) Cohort type tended to acquire their timeshare via an inheritance, gift or a divorce, preferred historical or cultural sites, was about 60 years of age (median) with a median income of $\$ 69,600$ and enjoyed travelling during their retirement years.

\section{STUDY PROBLEM}

In reference to identifying potential timeshare consumers, the studies conducted by Ragatz and Associates has been instrumental in moving away from past practices by applying a demographic and lifestyle approach to categorizing existing timeshare owners using the Cohorts segmentation tool. ${ }^{8}$ This practice is meritorious because the application of Cohorts provides resort management with information on individual likes and dislikes concerning such things as products and services, message content and delivery preferences for property products or services. It should also be noted that the Ragatz and Associates research aggregated timeshare owners irrespective of their type of ownership and as such did not focus entirely on timeshare consumers who participated in vacation clubs. This is important to note because the popularity of vacation clubs within the United States gained strong consumer acceptance beginning in the early 1990s when it was spearheaded by such leading, leisureproduct developers as Disney, Hilton and Fairfield Resorts. ${ }^{9}$ Since that time there has been relatively little public domain information describing the timeshare vacation club member or their timeshare property experiences. ${ }^{10,11}$ Therefore, the principal purpose of this case study was to determine if lifestyle (ie, Cohort type) differences existed among a randomly selected group of vacation club owners for a leading timeshare developer that sells timeshare interests under a points-based vacation club offering. A secondary function was to determine whether lifestyle differences were related to satisfaction levels as experienced by timeshare owners during their resort property experience. To date, such a model has not been reported in the academic literature. 
The Ragatz and Associates studies imply that the Looking Glass Cohort instrument is a useful tool in matching products/services and related marketing strategies to consumers when lifestyle preferences are known. The lingering question based on these Ragatz and Associates studies is whether lifestyle preferences may vary when the timeshare product is conveyed or sold under a vacation club offering.

\section{PURPOSE OF THE STUDY}

The primary focus of the current study examined the relationship between (a) the vacation club member's satisfaction as differentiated by 12 unique lifestyle groupings noted in the Cohorts lifestyle instrument (http://www. Cohorts.com/).

\section{Study understandings}

Prior to describing the methodology surrounding this study, it is important to review the characteristics of this timeshare developer's vacation club. When an individual purchases a specified amount of points alias an amount of time within this developer's vacation club, the owner has purchased a right to use the developer's resort facilities at one or more of developer's resorts (know as a resort group) for a specific type of accommodation and period of time. In its purest form, membership in this developer's vacation club means that a member has purchased a certain amount of points that in turn equates to a predetermined amount of resort usage (eg, time). From a practical perspective, vacation club members can use their points (ie, time) typically in each calendar year for a vacation at a number of resorts within the developer's resort network under certain time frame requirements or for other vacation packages such as a hotel stay.

In this study, four satisfaction indicators served as the dependent variables, each of which gauged different aspects of member satisfaction with vacation product offerings. These four indicators of satisfaction are (a) 'In general, how satisfied are you with your membership?', (b) 'How closely would you say your actual experiences matched your expectations at the time of your purchase?', (c) 'Overall, I was satisfied with my most recent vacation experience' and (d) 'In hindsight, what type of impact has being a Club Member had on your life and family's lives?'

\section{RESEARCH OBJECTIVES}

Two research objectives tested the relationship between vacation club member lifestyle (ie, Cohort) groupings and member satisfaction. The first objective profiles the Cohort types that are attracted to this developer's network of resorts. The second objective tests the relationship between Cohort groupings and satisfaction with this developer's resort products and services.

The study objectives were:

Research To determine the type of consumer that is attracted to a Objective 1: specific vacation club timeshare offering using the Looking Glass lifestyle segmentation instrument. 
Research To determine if significant differences exist between the Objective 2: Cohort types relative to the four satisfaction indices.

\section{STUDY METHODOLOGY}

The study population consisted of vacation club members from a leading timeshare company. At the time of administration, there were approximately 30,000 members within this vacation club, and 8,000 members were randomly selected for participation. Sample members were sent a survey with a business reply that yielded 2,544 out of 8,000 surveys for an overall response rate of 32.2 per cent.

\section{MEASURES AND SCALING}

Present study's independent variables

For the purposes of the present study, the three main Looking Glass Cohort groupings of Couples, Females and Males were examined by the

Table I: Independent variables - Cohort typology

\begin{tabular}{|c|c|}
\hline Coup & \\
\hline Alex \& Judith & Affluent empty nesters \\
\hline & $\begin{array}{l}\text { Dual-income, older couples who use their high discretionary incomes to enjoy all aspects of } \\
\text { the good life. }\end{array}$ \\
\hline Jeffrey \& Ellen & Affluent couples with kids \\
\hline & $\begin{array}{l}\text { Urban families who, despite having children at home, have sufficient financial resources to } \\
\text { own the latest high-tech products and to lead very active recreational and cultural lifestyles. }\end{array}$ \\
\hline Barry \& Kathleen & Affluent professional couples \\
\hline & $\begin{array}{l}\text { Educated, dual-income, childless couples who have connoisseur tastes and are focused on } \\
\text { their careers, staying fit and investing. }\end{array}$ \\
\hline Brett \& Tracey & Upcoming couples/hyperactive newlyweds \\
\hline & $\begin{array}{l}\text { Young, dual-income, childless couples whose energies are channeled into active sports, } \\
\text { outdoor activities, careers and their home lives. }\end{array}$ \\
\hline Danny \& Vickie & Teen-dominated families \\
\hline & $\begin{array}{l}\text { Middle-aged, middle-income families whose teen-dominated households keep busy with } \\
\text { outdoor activities, computers and video games. }\end{array}$ \\
\hline Burt \& Marilyn & Mature couples \\
\hline & $\begin{array}{l}\text { Comfortable, close-to-retirement homeowners who are active investors and who engage in } \\
\text { charitable activities, travel, politics and their grandchildren. }\end{array}$ \\
\hline Females & \\
\hline Elizabeth & Savvy career women \\
\hline & $\begin{array}{l}\text { Affluent, working women with sophisticated tastes, very active lifestyles and good investing } \\
\text { habits. }\end{array}$ \\
\hline Virginia & Upscale mature women \\
\hline & $\begin{array}{l}\text { Older women approaching or enjoying retirement, who travel and have upscale interests, } \\
\text { including charitable causes and investments. }\end{array}$ \\
\hline Allison & Educated working women \\
\hline & $\begin{array}{l}\text { Childless, professional women building their careers, developing sophisticated tastes and } \\
\text { staying fit. }\end{array}$ \\
\hline Andrea & Single moms with careers \\
\hline & $\begin{array}{l}\text { Successful, professional single mothers who balance their careers with the demands of raising } \\
\text { their children. }\end{array}$ \\
\hline Males & \\
\hline Harry & Well-to-do gentlemen \\
\hline & Mature men who are savvy about their investments, travel and politics. \\
\hline Randy & Single dads \\
\hline & $\begin{array}{l}\text { Single fathers who enjoy outdoor activities, their home workshops and electronic entertain- } \\
\text { ment with their kids. }\end{array}$ \\
\hline
\end{tabular}


Table 2: Dependent variables — satisfaction

\begin{tabular}{|c|c|c|}
\hline Dimension & Measure & Scale \\
\hline \multirow[t]{4}{*}{ Satisfaction indices } & $\begin{array}{l}\text { In general, how satisfied are you with your } \\
\text { membership }\end{array}$ & Scale: $I=$ Very satisfied to $5=$ Very dissatisfied \\
\hline & $\begin{array}{l}\text { After you joined, how closely were your } \\
\text { actual experiences with your expectations at } \\
\text { the time of purchase }\end{array}$ & $\begin{array}{l}\text { Scale: } I=\text { Exceed expectations to } 9=\text { Failed to } \\
\text { meet expectations }\end{array}$ \\
\hline & $\begin{array}{l}\text { Overall, I was satisfied with my most recent } \\
\text { vacation }\end{array}$ & $\begin{array}{l}\text { Scale: } I=\text { Strongly agree to } 5=\text { Strongly } \\
\text { disagree }\end{array}$ \\
\hline & $\begin{array}{l}\text { What type of impact has being a member in } \\
\text { this vacation club had on your life }\end{array}$ & Scale: $I=$ Very positive to $5=$ Very negative \\
\hline
\end{tabular}

researchers, retaining the general premises that underlie these lifestyle categories. Next, the categories are examined closer by superimposing the Looking Glass Cohort typology upon this sample determined that only 12 Cohort types comprised this developer's vacation club membership base. The general description of these Cohort types is contained in Table 1. The reason for reporting only 12 of the original 31 Cohort categories is that only 12 Cohort groupings were reflected in this developer's timeshare membership.

\section{Dependent variable descriptions}

There are four dependent variables concerning each club member's satisfaction with this developer's vacation club program. It should be noted that at the time of survey administration, each respondent was a member in good financial standing and had used their vacation club privileges within the current usage year (eg, 2004). Each satisfaction scale was set to an interval-type of scale as noted in Table 2 .

\section{Survey item consistency - satisfaction scales}

Prior to conducting any further statistical analysis, the researchers checked scale consistency by applying the Cronbach procedure to the proposed satisfaction indicators. The result is an inter-item consistency of 0.77 for the proposed satisfaction indicators. From a summative perspective, the Cronbach coefficient indicates a very high inter-item consistency for the measured dimension and surpassed the suggested 0.77 , providing evidence that the survey instrument consistently measures satisfaction in a uniform manner.

\section{FINDINGS AND DISCUSSION}

Research Objective 1: To determine the type of consumer that is attracted to a specific vacation club timeshare offering using the Looking Glass lifestyle segmentation instrument.

Before addressing the proposed research questions, a general description of the respondent profile is in order. The responding members 
for this vacation club are relatively affluent as noted by an average household income of 123,000 (US dollars), are in their peak earning years as specified by an average household age of 54, have less than 1 child at home and are largely couples with a smaller grouping of single males and females. The analysis indicates that this developer's resort product and services appeals to a limited number of lifestyle characteristics under the Cohort typology.

The Cohort profile noted in Table 3 suggests that this developer is predominately executing a niche segmentation strategy. Relative to the Cohort typology, 89.3 per cent of the respondents were couples, single females accounted for 6.7 per cent and single males comprised only 4 per cent of the sample. It should also be noted that these respondents enjoy leisure-oriented activities, are in their peak earning years, have no children residing at home, are active investors and enjoy recreational and leisure activities as offered at the resort. Overall, these findings are indicative of marketing efforts that are extremely focused in targeting and appealing to a group with similar demographic characteristics and lifestyle interests. This assertion is further supported by the considerable agreement as noted in the mean ratings and standard deviations for the four satisfaction indicators reported in Table 4.

Research Objective 2: To determine if significant differences exist between the Cohort types relative to the four satisfaction indices.

To ascertain if significant differences existed in response patterns concerning member satisfaction with this timeshare developer's vacation club offerings, the data were subjected to the analysis of variance (ANOVA) analyses, including the Gabriel post hoc statistical procedure. The Gabriel post hoc procedure is employed when the sample sizes are different, and will aid in determining which specific Cohorts have significant differences when the ANOVA model is statistically significant.

The ANOVA analysis incorporating the Gabriel procedure compared the responses for the 12 Cohort groups against (1) general satisfaction with the vacation club membership, (2) the match between the member's expectations with their actual vacation experience, (3) satisfaction with

Table 3: Cohort type profile

\begin{tabular}{lrllll}
\hline Couples & $\%$ & Females & $\%$ & Males & $\%$ \\
\hline Alex \& Judith & 21.6 & Elizabeth & 0.7 & Harry & 2.4 \\
Jeffrey \& Ellen & 26.1 & Virginia & 3.2 & Randy & 1.6 \\
Barry \& Kathleen & 15.7 & Allison & 0.9 & & \\
Brett \& Tracey & 5.3 & Andrea & 1.9 & \\
Danny \& Vickie & 3.7 & & & \\
Burt \& Marilyn & 16.9 & & & \\
Couple category=89.3\% & & & & \\
Female category=6.7\% & & & & \\
Male category=4.0\% & & & & \\
\hline
\end{tabular}


Table 4: Mean and standard deviation (s.d.) profile — satisfaction indices

\begin{tabular}{|c|c|c|c|c|c|c|c|c|}
\hline & \multicolumn{2}{|c|}{$\begin{array}{l}\text { General } \\
\text { satisfaction }\end{array}$} & \multicolumn{2}{|c|}{ Expectation match } & \multicolumn{2}{|c|}{$\begin{array}{l}\text { Recent visit } \\
\text { satisfaction }\end{array}$} & \multicolumn{2}{|c|}{ Impact on life } \\
\hline & Mean & s.d. & Mean & s.d. & Mean & s.d. & Mean & s.d. \\
\hline \multicolumn{9}{|l|}{ Cohort couples } \\
\hline Alex \& Judith & 1.69 & 0.79 & 3.83 & 1.76 & 1.64 & 0.67 & 1.91 & 0.6 \\
\hline Jeffrey \& Ellen & 1.88 & 0.92 & 4.23 & 2.01 & 1.69 & 0.79 & 1.87 & 0.7 \\
\hline Barry \& Kathleen & 1.89 & 0.83 & 3.90 & 1.84 & 1.76 & 0.76 & 1.95 & 0.8 \\
\hline Brett \& Tracey & 2.05 & 0.83 & 4.46 & 1.78 & 1.74 & 0.66 & 2.07 & 0.72 \\
\hline Danny \& Vickie & 2.00 & 0.81 & 4.38 & 1.99 & 1.84 & 0.76 & 1.89 & 0.56 \\
\hline Burt \& Marilyn & 1.72 & 0.72 & 3.85 & 1.91 & 1.64 & 0.64 & 1.85 & 0.64 \\
\hline Couples summary & 1.82 & 0.83 & 4.02 & 1.89 & 1.69 & 0.72 & 1.90 & 0.70 \\
\hline \multicolumn{9}{|l|}{ Cohort female } \\
\hline Elizabeth & 2.00 & 1.22 & 3.40 & 1.51 & 2.00 & 1.22 & 1.60 & 0.54 \\
\hline Virginia & 2.14 & 0.97 & 4.50 & 2.18 & 1.71 & 0.93 & 1.89 & 0.78 \\
\hline Allison & 2.00 & 0.50 & 3.78 & 1.98 & 1.78 & 0.66 & 1.89 & 0.78 \\
\hline Andrea & 1.68 & 0.47 & 4.53 & 1.92 & 1.90 & 0.91 & 1.89 & 0.69 \\
\hline Female summary & 1.97 & 0.81 & 4.31 & 2.02 & 1.77 & 0.90 & 1.87 & 0.69 \\
\hline \multicolumn{9}{|l|}{ Cohort male } \\
\hline Sean & 2.00 & 2.00 & 2.75 & 0.95 & 1.50 & 0.57 & 1.50 & 1.00 \\
\hline Harry & 2.40 & 1.05 & 4.47 & 1.92 & 2.07 & 0.96 & 2.07 & 0.70 \\
\hline Ryan & 4.00 & & 8.00 & & 2.00 & & 3.00 & \\
\hline
\end{tabular}

the member's most recent vacation experience and (4) the overall impact on the member's life. The ANOVA process indicated that significant differences existed across three (of the 12) Cohort groups on the measure of general satisfaction as well as member expectation (Table 5). These differences as detected by the Gabriel procedure uncovered that the Cohort types of Harry and Randy were significantly different from perceptions expressed by the Alex \& Judith Cohort group as noted in Tables $6 \mathrm{a}$ and $6 \mathrm{~b}$.

It may be that (single) male Cohort types, respectively, representing only 4 per cent of the membership, find themselves being 'outliers' when it comes to being satisfied with the vacation club offerings provided by this timeshare developer. Assuming that these Cohort types are a desired target market for this developer, the implication is that developer's recreational and leisure services need to be devised that better appeal to the Harry and Randy Cohort types. Simultaneously, this may be presumptuous because an alternative interpretation is that adequate services do exist but may not be adequately promoted or communicated to these Cohort types. Clearly, additional reflection is needed to determine where the gap between expectations and consumption occurs for these Cohort types.

\section{Implications}

Market segmentation is founded on the premise that differences in a customer characteristic will be reflected in differences in the type of product and services demanded. This statement certainly is fitting for this 
Table 5: ANOVA — between groups for all satisfaction indices

\begin{tabular}{llllll}
\hline & Between groups & d.f. & Mean square & $F$ & Significance level \\
\hline General satisfaction & 19.96 & 11 & 1.815 & 2.158 & $0.015^{*}$ \\
Expectation match & 79.34 & 11 & 7.213 & 1.811 & $0.048^{*}$ \\
Recent visit Satisfaction & 6.134 & 11 & 0.558 & 0.964 & 0.477 \\
Impact on life & 3.402 & 11 & 0.309 & 0.589 & 0.839 \\
\hline
\end{tabular}

Note: "Significance at the 0.05 level or less

Table 6a: Gabriel —ANOVA post hoc procedure for general satisfaction

\begin{tabular}{llll}
\hline & Mean difference & s.e. & Significance level \\
\hline Harry & & & \\
Alex \& Judith & 0.570 & 0.186 & $0.043^{*}$ \\
Jeffrey \& Allen & 0.406 & 0.185 & 0.571 \\
Barry \& Kathleen & 0.357 & 0.190 & 0.934 \\
Brett \& Tracey & 0.299 & 0.213 & 1.0 \\
Danny \& Vickie & 0.285 & 0.227 & 1.0 \\
Burt \& Marilyn & 0.504 & 0.189 & 0.206 \\
& & & 1.0 \\
Elizabeth & 0.083 & 0.369 & 1.0 \\
Virginia & 0.248 & 0.235 & 1.0 \\
Allison & 0.433 & 0.339 & 0.993 \\
Andrea & 0.476 & 0.267 & 1.0 \\
Randy & & &
\end{tabular}

Note: "Significance at the 0.05 level or less

Table 6b: Gabriel —ANOVA post hoc procedure for expectation match

\begin{tabular}{llll}
\hline & Mean difference & s.e. & Significance level \\
\hline Randy & & & \\
Alex \& Judith & 1.601 & 0.501 & $0.015^{*}$ \\
Jeffrey \& Allen & 1.228 & 0.498 & 0.234 \\
Barry \& Kathleen & 1.488 & 0.508 & 0.064 \\
Brett \& Tracey & 1.106 & 0.549 & 0.906 \\
Danny \& Vickie & 1.066 & 0.576 & 0.980 \\
Burt \& Marilyn & 1.470 & 0.206 & 0.064 \\
& & & 1.0 \\
Elizabeth & 1.815 & 0.896 & 1.0 \\
Virginia & 0.882 & 0.593 & 0.925 \\
Allison & 1.629 & 0.795 & 1.0 \\
Andrea & 0.829 & 0.658 & 0.989 \\
Harry & 1.122 & 0.618 & \\
\hline
\end{tabular}

Note: *Significance at the 0.05 level or less

developer's timeshare consumers relative to their consumption and satisfaction of recreational and leisure services offered at the property level. Although the lack of a sought-after recreational or leisure service latter may be perceived as minor in some instances, any difference may impact the consumer's perception of the property's quality and value, and 
ultimately impact the more global evaluation of the consumption experience, customer satisfaction. Segmentation, therefore, becomes a market-driving force affecting such elements as physical property design and location as well as 'intangible attributes' such as status, luxury, uniqueness and adventurous.

The findings of this study imply that the application of a Cohort-defining instrument by developers upon timeshare consumers is a valuable exercise in that unique consumer profiles existed for the purchasers of this developer's vacation club. Of further strategic importance is the observation that the Cohort profiles of the current study were distinctive in comparison to the larger collection of profiles identified in the 2003 Ragatz study. It appears that these differences are indeed related to narrower demographic and lifestyle characteristics that map to this developer's resort property offerings. Finally, while the alignment of a market niche strategy with the satisfaction measures appears strong, some Cohort groups were identified for possible 'tweaking' of the product/service mix delivered, or perceived to be delivered, to them. The improvement in their experiences would translate into improved levels of satisfaction on the items measured. This knowledge assists timeshare developers and management in focusing their product development and service delivery efforts to a segment-by-segment basis.

\section{FUTURE DIRECTIONS}

The findings of the present study indicate that it is worthy for each timeshare developer to profile their existing consumers via the application of a lifestyle segmentation scheme. Doing so aids in identifying 'unique' needs associated with a Cohort segment that can then be translated into salient actionable modifications in the product offerings (vacation and leisure preferences) to be delivered to each specific segment. Once these attitudes, opinions and product consumption preferences are identified, the timeshare developer can increase the likelihood that purchaser expectations are initially met and therefore maintained by the design and delivery of appropriate product packaging and services resulting in satisfied property owners. Additionally, it allows the company to focus their marketing efforts to new markets or to the existing markets that are most successful for them.

\section{References}

1. Upchurch, R. and Kaufman, T. (2005) ARDA Education Institute Resource Manual, American Resort Development Association, Washington, DC.

2. Moscardo, G. (2004), 'Escaping the jungle: An exploration of the relationships between lifestyle market segments and satisfaction with a nature based tourism experience', Journal of Quality Assurance in Hospitality \& Tourism, Vol. 5, No. 2, pp. 75-94.

3. Thyne, M., Davies, S. and Nash, R. (2004) A Lifestyle Segmentation Analysis of the Backpacker Market in Scotland: A Case Study of the Scottish Youth Hostel Association.

4. Burlingame, C. (2001) 2000 Vacation Ownership Sales Leaders, Vacation Ownership World, January, pp. 8-9.

5. Scott, N. and Parfitt, N. (2004), 'Lifestyle segmentation in tourism and leisure: Imposing order or finding it?' Journal of Quality Assurance in Hospitality and Tourism, Vol. 5, No. 2-4, pp. $121-140$. 
6. Tucker, H. and Lynch, P. (2004), 'Host-guest dating: The potential of improving the customer experience through host-guest psychographic matching', Journal of Quality Assurance in Hospitality \& Tourism, Vol. 5, No. 2, pp. 11-33.

7. http://Cohorts.com/about_looking_glass.html18 November 2005.

8. Ragatz and Associates (2003) Resort Timesharing in the United States, Ragatz and Associates, Eugene, OR

9. Refer to reference ${ }^{\mathrm{i}}$.

10. Upchurch, R. (2002) ARDA Education Institute Resource Manual, American Resort Development Association, Washington, DC.

11. Upchurch, R. and Gruber, K. (2002), 'The evolution of a sleeping giant: resort timesharing', International Journal of Hospitality Management, Vol. 21, No. 3, pp. 211-225. 